\title{
Effects of Heat Treatment Conditions on the Mechanical Properties of Orthodontic Stainless Steel Wires
}

\author{
Keun-Taek Oh${ }^{1}$, Chung-Ju Hwang ${ }^{2}$ and Kyoung-Nam Kim ${ }^{1}$ \\ ${ }^{1}$ Research Institute of Dental Biomaterials and Bioengineering, College of Dentistry, Yonsei University, \\ 134 Shinchon-Dong, Seodaemun-Gu, Seoul, 120-752, Korea \\ ${ }^{2}$ Department of Orthodontics, College of Dentistry, Yonsei University, \\ 134 Shinchon-Dong, Seodaemun-Gu, Seoul, 120-752, Korea
}

The purpose of this study was to evaluate mechanical properties of the orthodontic wires according to heat treatment environments and cooling methods. Four types of wires were heat-treated in air, argon and vacuum at $500^{\circ} \mathrm{C}$, for 6 min, and were then either cooled in the furnace or a water bath. Increases in microhardness, maximal strength, yield strength and Young's modulus of the orthodontic wires after heat treatment were approximately $0.4-22.9 \%, 2.9-14.8 \%, 3.7-14.4 \%$ and $2.5-9.0 \%$, respectively. This was considered to be because of mainly precipitation hardening and additionally subgrain formation by the heat treatment. Yield strength and microhardness of the heat-treated wires were also significantly dependent upon the cooling methods. The microhardness and yield strength of the water-cooled wires were lower than those of the furnace cooled wires. This was attributed to the precipitation degree of chromium carbides dependent on cooling rate. Heat treatment in an air oxidized the surface of the wires, and the mechanical properties and surface cleanness of the water-cooled wires were poorer than those of the furnace-cooled wires. Conclusively, orthodontic wires should be heat-treated in vacuum conditions or an inert gas environment after plastic deformation and should be cooled in a furnace in order to inhibit surface oxidation, maximize corrosion resistance and improve the mechanical properties.

(Received March 15, 2002; Accepted July 22, 2002)

Keywords: heat treatment, orthodontic wires, stainless steel, mechanical properties

\section{Introduction}

Orthodontic wires generate biomechanical forces communicated through brackets for tooth movement. Therefore, the orthodontist should consider many factors, such as the amount of force delivery that is desired, the working range or springback, the formability or ease of manipulation, and the need for soldering or welding to assemble an appliance. In vivo corrosion, with the release of metal ions, and the ensuing biocompatibility concerns for the patient are also important factors. ${ }^{1)}$

Orthodontic stainless steel wires undergo cold working processes, such as rolling, pressing and drawing, and cold drawn wires have a large number of dislocations and point defects, such as vacancies or interstitial atoms in the grains. In addition, cold working induces phase transformations and distorts the grains into long fibrous shapes, elongated along the length of the wire. Therefore, cold working can improve mechanical properties, such as the strength and hardness of wires. ${ }^{2)}$ However, because orthodontic wires are often deformed plastically by the orthodontist's manipulations, as the occasion demands, internal stresses may be incorporated into the wire. The resultant cold working may alter the elasticity and mechanical properties of the wire, leading to a possible increase in brittleness. Therefore, after the drawing process and the formation of a loop, helical spring, archform etc, the wire is heat-treated at a lower temperature to relieve partly stress. This heat treatment improves the elasticity, stability of the dislocations and the shape of the wire. ${ }^{3)}$ However, conventionally, the wires are heat-treated for a few minutes at a higher temperature in an air.

Funk $^{4}$ reported that heat treatment was very effective for improving the elastic properties of orthodontic stainless steel wires and that a temperature of $450^{\circ} \mathrm{C}$ was optimum. Backofen and Gales ${ }^{5}$ ) also demonstrated a marked increase in the elastic strength (yield strength of loops or springs) upon heat treatment. Kohl ${ }^{6)}$ reported the relationship between physical, mechanical properties and the metallurgical microstructure of orthodontic wires. Howe et al., ${ }^{7)}$ demonstrated the annealing effect on mechanical properties of stainless steel wires. In particular, these workers showed that type 316 stainless steel wire had a higher elasticity than 302 stainless steel. They suggested that stainless steel wires need to be heat-treated in order to relieve the stresses developed during cold working. Moreover, Gardiner and Aamodt ${ }^{8)}$ suggested that orthodontic wires could also be stress-relieved during the soldering process. Skinner ${ }^{9)}$ reported that, when an external stress deforms a metal plastically, the positions of the metallic atoms in the crystal lattice could be changed. This can therefore interfere with neighboring metallic atoms, and as a result, a higher external force than the initial deformation is needed to accomplish further deformations, thus increasing the wire strength. Thurow ${ }^{10)}$ suggested that wire heat treatment could reduce the adverse effect of residual stresses and improve the elasticity, microstructure and size stability of wire used in orthodontic procedures.

As demonstrated above, many researchers have reported improvements in the mechanical properties of orthodontic wires caused by heat treatment. ${ }^{4-7,10)}$ However, heat treatment has been generally performed in ambient air, at high temperature (about $500^{\circ} \mathrm{C}$ ) for a few minutes. This of course can reduce the corrosion resistance of orthodontic wires, and such damage to the metal's corrosion resistance can result in the release of metallic ions, which can have adverse effects on the human body. ${ }^{11)}$ Little research has been done on orthodontic wire properties according to different heat treatment 
environments, including the cooling methods. Therefore, the objectives of the present study were to determine the effects of both the heat treatment environment and the cooling method on the wire properties, and to suggest an optimum and effective heat treatment to maximize corrosion resistance and the mechanical properties of the heat-treated wires.

\section{Materials and Methods}

Four types of orthodontic stainless steel wires were included in the investigation: Remanium (Dentaurum, Ispringen, Germany), Permachrome (3M Unitek, Monrovia, US), Colboloy (G\&H, Greenwood, US), and Orthos (Ormco, Glendora, US). Chemical compositions of the orthodontic wires used in this study are presented in Table 1. All the products were supplied as straight lengths with cross sections of $0.41 \times 0.56 \mathrm{~mm}$. Heat treatment was performed either in vacuum (at ca. $1.33 \times 10^{-3} \mathrm{~Pa}$ ), air or argon (above $1.01 \times 10^{5} \mathrm{~Pa}$ ) at $500^{\circ} \mathrm{C}$, for $6 \mathrm{~min}$, and cooling was accomplished in either a water bath or a furnace. The heating rate was $10^{\circ} \mathrm{C} / \mathrm{min}$ and the cooling rate, in the furnace, $5^{\circ} \mathrm{C} / \mathrm{min}$. The as-received condition of each wire was included in all the testing, and was used as the control. To investigate the cause of the change in the wire's mechanical properties according to the heat treatment, a hardness test was carried out for completely stressrelieved orthodontic wires by full-annealing, performed at $1050^{\circ} \mathrm{C}$, for $6 \mathrm{~min}$, and then cooling in the furnace.

A bending and a microhardness test were carried out to evaluate the mechanical properties of the heat-treated orthodontic wires. To measure the hardness value, the wires were mounted in an epoxy resin, polished with \#2000 SiC paper, ultrasonically cleaned in an ethylalcohol solution, and then dried. A micro Vickers hardness tester (MXT- $\alpha$ 7E model, Matsuzawa Seiki Co., Japan) was used for the test, and the hardness measurement was done at a loading of $100 \mathrm{~g}$, nine and five times per sample in the longitudinal and cross section, respectively. The three point bending test was performed at a crosshead speed of $5 \mathrm{~mm} / \mathrm{min}$, using a full-scale load range of $10 \mathrm{kgf}$, using a tensile test machine (Series IX Automated Materials Testing System, Instron Corp., Carrtorr, USA). Each sample was tested five times and maximal and yield bending strength $(0.2 \%$ offset $)$, and Young's modulus were determined. Five specimens nominally $7.5 \mathrm{~cm}$ in length for the bending test were prepared and then put on the threepoint bending test jig.

Phase identification by an XRD (X-ray diffractometer, D-Max Rint 2400 model, Rigaku, Japan) was performed using $\mathrm{K} \alpha$ ray of $\mathrm{Cu}$ target in the scan range of $30^{\circ}-95^{\circ}$, at a scan rate of $4 \% \mathrm{~min}$. The phase fractions of each wire were determined from the diffraction pattern by direct comparison

Table 1 Chemical compositions of the orthodontic wires used in this study (mass\%).

\begin{tabular}{lcccccc}
\hline Specimen & $\mathrm{Fe}$ & $\mathrm{Cr}$ & $\mathrm{Ni}$ & $\mathrm{Si}$ & $\mathrm{C}$ & $\mathrm{S}$ \\
\hline Remanium & 71.25 & 18.75 & 8.29 & 1.13 & 0.11 & 0.006 \\
Permachrome & 69.17 & 19.92 & 9.00 & 1.56 & 0.08 & 0.003 \\
Colboloy & 70.42 & 19.71 & 8.65 & 0.79 & 0.08 & 0.002 \\
Orthos & 66.68 & 19.45 & 8.79 & 1.77 & 0.08 & 0.004 \\
\hline
\end{tabular}

method among the quantitative analysis methods by X-ray diffraction in the samples with the multiphase. ${ }^{12)}$ For the quantitative evaluation of the wire phase fractions the (200) planes of austenite and martensite was selected.

Statistical analysis was performed using Kruskal-Wallis test, ${ }^{13)}$ and a significant difference was accepted at the $95 \%$ confidence interval. Significant differences in bending properties according to heat treatment condition in each wire were decided by Scheffe grouping method. ${ }^{14)}$

\section{Results}

\subsection{Micro Vickers hardness}

The results of hardness testing are presented in Fig. 1. In the case of the control group, which was not heat treated, the hardness value of Remanium was $456( \pm 14) \mathrm{Hv}$, which was the lowest value recorded in the control group, and

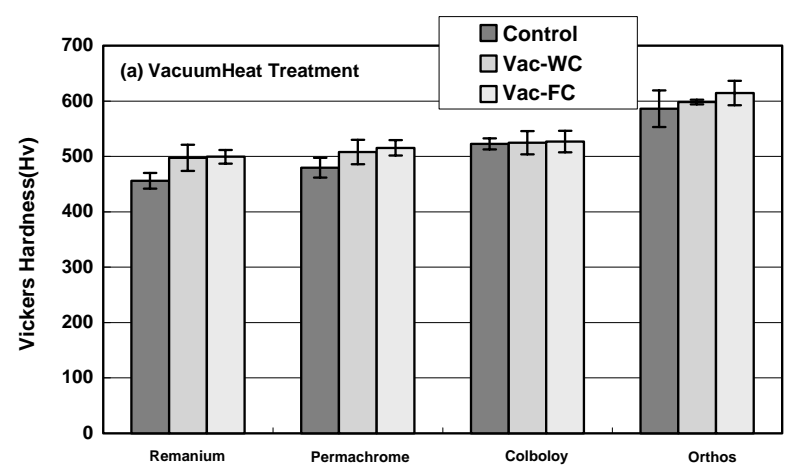

(a)

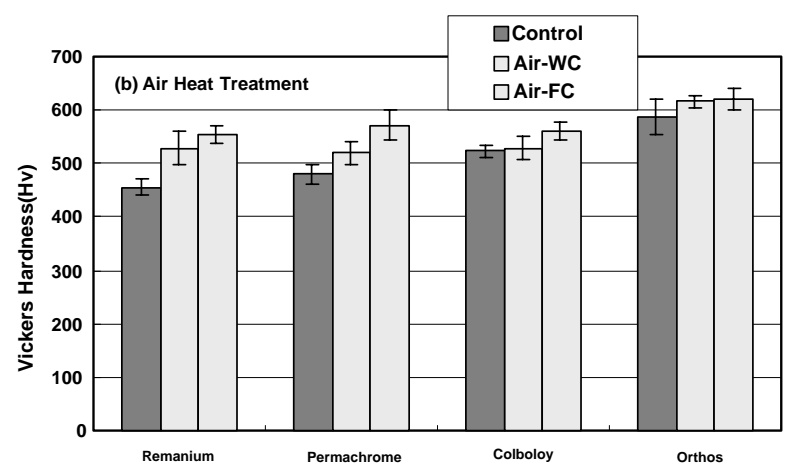

(b)

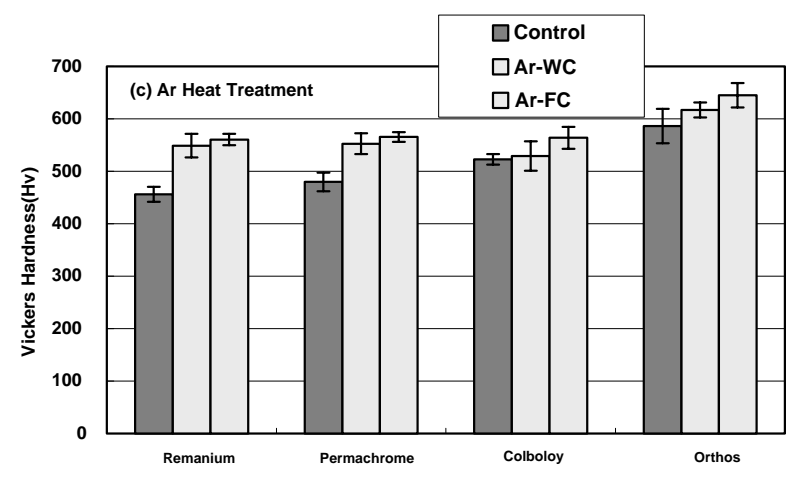

(c)

Fig. 1 Microhardness (Hv) of the stress relieving heat-treated wires. 
Table 2 Maximal strength (bending) of the heat-treated wires according to heat treatment conditions.

\begin{tabular}{|c|c|c|c|c|}
\hline \multirow{2}{*}{ Sample } & \multicolumn{4}{|c|}{ Bending maximal strength $(\mathrm{MPa})$} \\
\hline & & Vacuum & Air & $\mathrm{Ar}$ \\
\hline \multirow{3}{*}{ Remanium } & Control & & $1210.1 \pm 7.0^{\mathrm{a}}$ & \\
\hline & Water cooling & $1325.2 \pm 12.3^{\mathrm{b}}$ & $1288.7 \pm 12.2^{\mathrm{b}}$ & $1327.5 \pm 20.0^{b}$ \\
\hline & Furnace cooling & $1309.5 \pm 7.3^{\mathrm{b}}$ & $1339.5 \pm 11.4^{\mathrm{b}}$ & $1332.0 \pm 13.4^{\mathrm{b}}$ \\
\hline \multirow{3}{*}{ Permachrome } & Control & & $1279.3 \pm 3.3^{\mathrm{a}}$ & \\
\hline & Water cooling & $1374.7 \pm 12.3^{\mathrm{b}}$ & $1390.8 \pm 12.6^{b}$ & $1361.2 \pm 7.5^{\mathrm{b}}$ \\
\hline & Furnace cooling & $1404.7 \pm 11.9^{\mathrm{b}}$ & $1364.2 \pm 10.7^{\mathrm{b}}$ & $1386.9 \pm 14.2^{b}$ \\
\hline \multirow{3}{*}{ Colboloy } & Control & & $1229.1 \pm 25.1^{\mathrm{a}}$ & \\
\hline & Water cooling & $1393.4 \pm 12.2^{\mathrm{bc}}$ & $1310.3 \pm 15.2^{\mathrm{ab}}$ & $1343.2 \pm 28.6^{\mathrm{bc}}$ \\
\hline & Furnace cooling & $1411.0 \pm 16.8^{c}$ & $1302.2 \pm 9.5^{\mathrm{ab}}$ & $1325.2 \pm 8.7^{\mathrm{abc}}$ \\
\hline \multirow{3}{*}{ Orthos } & Control & & $1398.5 \pm 21.2^{\mathrm{a}}$ & \\
\hline & Water cooling & $1471.8 \pm 27.0^{\mathrm{ab}}$ & $1438.4 \pm 8.5^{\mathrm{a}}$ & $1439.4 \pm 20.3^{\mathrm{a}}$ \\
\hline & Furnace cooling & $1488.8 \pm 3.4^{\mathrm{ab}}$ & $1447.7 \pm 8.3^{\mathrm{a}}$ & $1540.4 \pm 20.8^{b}$ \\
\hline
\end{tabular}

a,b,c : significantly different according to heat treatment conditions $(p<0.05)$.

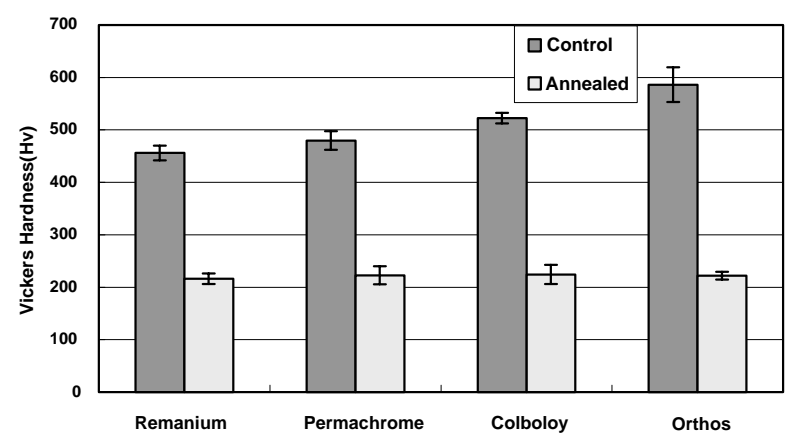

Fig. 2 Microhardness of the control wires and the full annealed wires.

the hardness of Permachrome, Colboloy, and Orthos were 480 $( \pm 18) \mathrm{Hv}, 523( \pm 10) \mathrm{Hv}$, and 586 $( \pm 33) \mathrm{Hv}$, respectively. Four types of orthodontic wires showed an increase in hardness after heat treatment. Heat treatment of the orthodontic wires increased the hardness value of the controls by 0.4 $22.9 \%$, depending on the type of orthodontic wire, the heat treatment environment and the cooling method used. Wires heat-treated in an argon environment had higher hardness values than those treated in a vacuum; both were higher than the control. Furnace cooled wires showed higher hardness values than the water-cooled wires. Remanium, showed the highest relative hardness increase and Colboloy the lowest compared to their respective controls. To investigate the cause of the strength and elastic modulus observed by heat treatment, the hardness tests were carried out on fully annealed wires. Results are shown in Fig. 2. There were significant differences between the hardness values of the full-annealed wires and the controls. The control wires had a high hardness value by virtue of the plastic deformation induced during the wire drawing process. The hardness values of the full-annealed wires (approximately $220 \mathrm{Hv}$ ) were a little bit higher than that of conventional stainless steels (304 stainless steels) in an annealed state (approximately $180 \mathrm{Hv}$ ). Work hardening effect by cold drawing is more than double hardness of annealed stainless steel wire. Among the control wires, Orthos had the highest hardness value and Remanium the lowest, but the four types of the wires when in the full-annealed state had similar hardness values.

\subsection{Bending properties}

From the bending test, the measured values of maximal bending strength, yield strength and elastic modulus according to the heat treatment conditions are shown in Tables 2-4. In the case for the hardness results, the strength and elastic modulus of the heat-treated wires increased. Maximal strength showed an increment of around 2.9-14.8\%, corresponded to a yield strength increment of approximately $3.7-$ $14.4 \%$, and an elastic modulus increment of 2.5-9.0\%, compared with the corresponding controls. In the case of the heat-treated and control wires, the maximal bending strength, yield strength and elastic modulus of Orthos were highest, and those of Remanium lowest.

There was no significant difference in maximal strength, but slightly significant difference in the yield strength among the wires according to heat treatment environments and cooling methods. Water-cooled wires had lower yield strength than furnace cooled wires. In terms of the elastic modulus, the wires heat-treated in a vacuum showed relatively greater increments than the others, however, the differences in the elastic moduli of the wires were small with respect to the cooling methods. The elastic modulus of Orthos showed a significant difference with respect to the cooling methods, and water-cooled wires had the lower elastic moduli than furnace cooled wires.

\subsection{Phase fractions of the wires}

The austenitic and martensitic phase fractions obtained by the direct comparison method are presented in Fig. 3. It was assumed that .austenite fraction + martensite fraction $=1$. So only austenite fraction is shown in Fig. 3. The difference in the phase fractions of the different types of the wires was significant; the austenitic phase fractions of Remanium, Permachrome, Colboloy, and Orthos were $79.9( \pm 2.78) \%$, $76.3( \pm 2.62) \%, 42.8( \pm 2.44) \%$, and $37.8( \pm 3.24) \%$, respectively. 
Table 3 Yield strength (bending) of the heat-treated wires according to heat treatment conditions.

\begin{tabular}{|c|c|c|c|c|}
\hline \multirow{2}{*}{ Sample } & \multicolumn{4}{|c|}{ Bending yield strength (MPa) } \\
\hline & & Vacuum & Air & $\mathrm{Ar}$ \\
\hline \multirow{3}{*}{ Remanium } & Control & & $1094.9 \pm 7.4^{\mathrm{a}}$ & \\
\hline & Water cooling & $1202.5 \pm 13.0^{\mathrm{b}}$ & $1183.8 \pm 15.0^{\mathrm{b}}$ & $1228.9 \pm 22.2^{\mathrm{b}}$ \\
\hline & Furnace cooling & $1193.6 \pm 12.5^{\mathrm{b}}$ & $1227.9 \pm 14.4^{\mathrm{b}}$ & $1222.8 \pm 16.7^{\mathrm{b}}$ \\
\hline \multirow{3}{*}{ Permachrome } & Control & & $1146.2 \pm 9.9^{\mathrm{a}}$ & \\
\hline & Water cooling & $1259.1 \pm 9.6^{\mathrm{b}}$ & $1249.3 \pm 13.7^{\mathrm{b}}$ & $1244.2 \pm 2.3^{\mathrm{b}}$ \\
\hline & Furnace cooling & $1289.7 \pm 8.1^{b}$ & $1266.6 \pm 9.3^{\mathrm{b}}$ & $1274.8 \pm 13.3^{\mathrm{b}}$ \\
\hline \multirow{3}{*}{ Colboloy } & Control & & $1122.1 \pm 19.1^{\mathrm{a}}$ & \\
\hline & Water cooling & $1261.1 \pm 7.9^{\mathrm{bc}}$ & $1191.1 \pm 15.1^{\mathrm{ab}}$ & $1221.7 \pm 30.0^{\mathrm{bc}}$ \\
\hline & Furnace cooling & $1283.4 \pm 13.6^{\mathrm{c}}$ & $1212.5 \pm 11.5^{\mathrm{abc}}$ & $1210.7 \pm 10.3^{\mathrm{abc}}$ \\
\hline \multirow{3}{*}{ Orthos } & Control & & $1271.6 \pm 20.1^{\mathrm{a}}$ & \\
\hline & Water cooling & $1331.3 \pm 12.7^{b}$ & $1318.7 \pm 8.8^{\mathrm{b}}$ & $1327.5 \pm 17.8^{\mathrm{b}}$ \\
\hline & Furnace cooling & $1371.4 \pm 21.6^{\mathrm{b}}$ & $1331.8 \pm 11.0^{\mathrm{ab}}$ & $1365.1 \pm 26.6^{\mathrm{b}}$ \\
\hline
\end{tabular}

a,b,c: significantly different according to heat treatment conditions $(p<0.05)$.

Table 4 Elastic Modulus(bending) of the heat-treated wires.

\begin{tabular}{|c|c|c|c|c|}
\hline \multirow{2}{*}{ Sample } & \multicolumn{4}{|c|}{ Elastic modulus (GPa) } \\
\hline & & Vacuum & Air & $\mathrm{Ar}$ \\
\hline \multirow{2}{*}{ Remanium } & Control & & $160.6 \pm 0.3^{\mathrm{a}}$ & \\
\hline & Furnace cooling & $170.0 \pm 0.7^{\mathrm{b}}$ & $168.3 \pm 1.6^{b}$ & $169.6 \pm 0.6^{\mathrm{b}}$ \\
\hline \multirow{3}{*}{ Permachrome } & Control & & $164.5 \pm 0.5^{\mathrm{a}}$ & \\
\hline & Water cooling & $174.6 \pm 0.3^{b c}$ & $171.8 \pm 0.7^{\mathrm{b}}$ & $171.0 \pm 0.8^{\mathrm{b}}$ \\
\hline & Furnace cooling & $176.1 \pm 0.8^{\mathrm{c}}$ & $171.5 \pm 0.9^{b}$ & $172.1 \pm 0.9^{\mathrm{b}}$ \\
\hline \multirow{3}{*}{ Colboloy } & Control & & $161.8 \pm 1.6^{\mathrm{a}}$ & \\
\hline & Water cooling & $175.9 \pm 1.3^{\mathrm{c}}$ & $165.7 \pm 1.5^{\mathrm{ab}}$ & $170.4 \pm 1.5^{\mathrm{bc}}$ \\
\hline & Furnace cooling & $176.2 \pm 1.2^{\mathrm{c}}$ & $167.4 \pm 0.6^{\mathrm{ab}}$ & $168.1 \pm 0.5^{\mathrm{ab}}$ \\
\hline \multirow{3}{*}{ Orthos } & Control & & $171.3 \pm 1.5^{\mathrm{a}}$ & \\
\hline & Water cooling & $179.6 \pm 0.8^{\mathrm{b}}$ & $175.9 \pm 1.8^{\mathrm{bc}}$ & $177.9 \pm 1.2^{\mathrm{b}}$ \\
\hline & Furnace cooling & $182.1 \pm 0.8^{\mathrm{b}}$ & $178.1 \pm 0.9^{\mathrm{b}}$ & $180.5 \pm 1.5^{\mathrm{b}}$ \\
\hline
\end{tabular}

a,b,c: significantly different according to heat treatment conditions $(p<0.05)$.

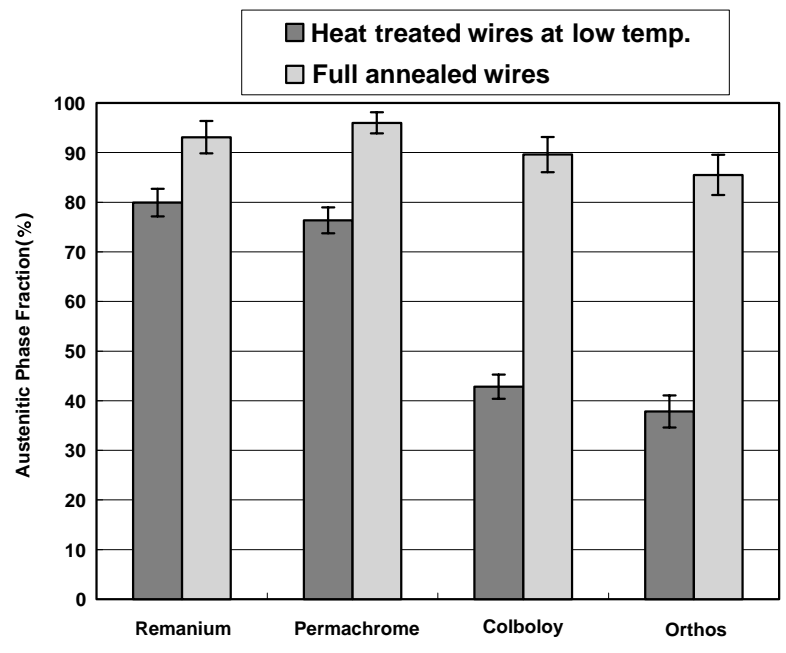

Fig. 3 The austenitic phase fractions (\%) of the orthodontic wires.

\section{Discussion}

A considerable amount of prior work has established that heat treatment does affect the mechanical properties of cold worked stainless steels. In particular, heat treatment causes a marked increase in elastic strength of loops or springs. There is good reason to conclude that in the orthodontic field, as in the other fields of stainless steel applications, improved elastic strength is the most important physical property. Many researches have shown that the relevant mechanical property values of orthodontic stainless steel wire can be altered somewhat by using a low-temperature heat treatment. Many studies have been conducted to determine the optimum temperature and time combination for the heat treatment of various types of orthodontic wire. Investigators have commented on the directions and extents of physical property value changes resulting from heat treatment, and although disagreements exist among researchers regarding the detail of these changes, the overall effectiveness of such a heat treatment is generally accepted. It is recommended that such heat treatment should be carried out for a long time at the relatively low temperature of $\left(200-350^{\circ} \mathrm{C}\right)$, however, more normally, the wires have been heat treated for a few minutes at higher temperature (400$550^{\circ} \mathrm{C}$ ), especially, in air. We believed that this could reduce the corrosion resistance of the orthodontic wires by the surface oxidation. Therefore, we undertook the present study 
to address the effects of both the heat treatment environment and the cooling method on wire properties, and to suggest optimum and effective heat treatment methods to improve the mechanical properties and minimize any damage with respect to the corrosion resistance of the heat-treated wires.

Heat treatment increased the microhardness, strength and Young's modulus of four types of orthodontic wires. This was considered to be because of mainly precipitation hardening and additionally subgrain formation by the heat treatment.

From the results of hardness testing, Remanium had the lowest value and Orthos the highest in the control group. The four types of orthodontic wires examined showed hardness increases after heat treatment. Heat treatment of the orthodontic wires increased hardness by $0.4-22.9 \%$ compared to the respective controls, depending on the types of orthodontic wires, and the heat treatment environment and cooling method used. In the case of the heat-treated and control wires, the maximal bending strength, yield strength and elastic modulus of Orthos were the highest among the measured wires, and those of Remanium the lowest.

These wires belong to either type 302 ( 0.08 mass\% above) or 304 austenitic stainless steel according to the carbon content. Therefore, Remanium can be classified as a type 302 stainless steel. Oh et al. ${ }^{15)}$ reported that Remanium contains more fine carbides than in that of the other wires. It was considered that Orthos had the highest hardness and strength among the wires used in this study, because of a higher degree of work hardening, as indicated by the results it also had the highest martensitic phase fraction. Among many factors that can improve the mechanical properties of the wires, the most dominant factor was considered to be the work hardening induced during cold working. The wires with high martensitic phase fraction have probably experience a high degree of working hardening that is a deformation that can induce a phase transformation due to the action of high stress. There were significant differences in the hardness values of fully annealed wires and the controls. The control wires had enhanced hardness value due to the plastic deformation induced during the wire drawing process. The hardness values of the full-annealed wires (approximately $220 \mathrm{Hv}$ ) were a little higher than that of conventional stainless steel in an annealed state (approximately $180 \mathrm{Hv}$ ). The work hardening effect produced by the cold drawing process is more than double hardness of the conventional stainless steel. Among the control wires, Orthos had the highest hardness value and Remanium the lowest, but all four types of wires in the fully annealed state had the similar hardness values. Therefore, the increased mechanical properties, such as strength and hardness are considered to be caused by the degree of working.

In terms of the level of stress relief, Howe et al. ${ }^{7)}$ reported that approximately $12.0-40.0 \%$ of stress is relieved by heat treatment. Lane and Nikolai, ${ }^{16)}$ reported 11.8 and $13.9 \%$ mean increases in mesiodistal stiffness and elastic ranges, respectively. Naturally, the magnitude of relief depends on the nature of the stress, the heat treatment time and temperature and the materials used. Nikolai ${ }^{17)}$ reported that, when the wires were plastically deformed by cold working, such as bending or looping, heat treatment could reduce some of residual stress and increase the ductility of the wires. However, the elastic limit, elastic energy and yield strength de- pended on the type of wire, the wire diameter and the degree of work hardening.

In terms of metallurgical recovery, heat treatment at a lower temperature results in a stable arrangement of the dislocation that exist in wires, and the linear arrangements of slip planes between dislocations forms polygonized subgrains. Moreover, the motion of the dislocation is inhibited because of the formation of subgrains with a low boundary angle in the grains. This phenomenon is considered to increase partly the mechanical properties of the heat-treated wire.

There was significant difference of the yield strength and the hardness of the wires according to the cooling methods investigated in this study. Water-cooled wires had a lower yield strength and hardness than those of the furnace cooled wires. The reason is believed to be due to the amount difference of chromium carbides precipitated in grain boundary between furnace- and water-cooling. In terms of furnace cooling, the wires were cooled slowly at the rate of $3-5^{\circ} \mathrm{C}$, while in the water cooling, they were cooled quickly from the heat treatment temperature to water temperature of approximately $15^{\circ} \mathrm{C}$, which inhibited chromium carbides precipitation.

Oh et al. ${ }^{15)}$ reported that heat treatment of stainless steel wires in an air environment formed very thick uneven iron and chromium oxides on the surface, but heat treatment in a vacuum or in an argon environment inhibited both surface oxidation. After heat treatment, furnace cooling inhibited surface contamination of the wires better than did water-cooling. Water-cooled wires had a rough surface, as oxide or hydroxide layers were formed by reactions with the cooling water. It is thought that water-cooling forms layers that are not dense enough to play a key role in protecting the metals from corrosion in the oral cavity.

Typically, the oxidized surface consists of granules and flakes, which sometimes may be partly separated from the bulk of the wire. For $\mathrm{Fe}-\mathrm{Cr}$ alloys heated above $500^{\circ} \mathrm{C}$, it has been demonstrated that the oxide may spall on cooling. Furthermore, during the high temperature oxidation the underlying zone of alloy will be depleted in chromium, thus making the alloy more prone to corrosion.

Heat treatment at high temperature impaired corrosion resistance and reduced mechanical properties. ${ }^{18)}$ Heating at approximately $430^{\circ} \mathrm{C}$ precipitates chromium carbides in the grain boundaries of the metastable stainless steel. This can induce intergranular corrosion in stainless steels with a high carbon content. This carbide precipitation occurs at a lower temperature if the stainless steel has also been cold-worked. To restrict localized corrosion of the chromium depletion zone by carbide precipitation, a cold-drawn stainless steel wire with a low carbon content should be used.

Overall, heat treatment is applied to orthodontic wires to relieve stresses caused by cold working and the orthodontist's manipulations. Although heat treatment can improve the mechanical properties of the wire, the corrosion resistance may be damaged by heat treatment methods. In conclusion, orthodontic wires should be heat-treated in either vacuum conditions or an inert gas environment after plastic deformation and must be cooled in a furnace, in order to inhibit surface oxidation, minimize the release of metal ions by corrosion and improve mechanical properties. 


\section{Conclusions}

(1) Heat treatment increased the microhardness, strength and Young's modulus of four types of orthodontic wires. The increased fractions of microhardness, maximal strength, yield strength and Young's modulus of the orthodontic wires caused by heat treatment were approximately $0.4-22.9 \%$, $2.9-14.8 \%, 3.7-14.4 \%$ and $2.5-9.0 \%$, respectively. This was considered to be because of mainly precipitation hardening and additionally subgrain formation by the heat treatment.

(2) There was significant difference of the yield strength and the hardness of the wires according to the cooling methods used in this study. Water-cooled wires had a lower yield strength and hardness than those of the furnace cooled wires. This is believed to be depended on the degree of chromium carbides formation.

In conclusion, orthodontic wires should be heat-treated either in vacuum or in an inert gas environment after plastic deformation and cooled in the furnace, in order to inhibit corrosion and improve mechanical properties.

\section{Acknowledgements}

This work was supported by Brain Korea 21 Project for Medical Science, Yonsei University in 2002.

\section{REFERENCES}

1) W. A. Brantley: Orthodontic Materials, ed. by W. A. Brantley and T. Eliades (Thieme Stuttgart, New York, 2001) pp. 77-103.
2) H. Y. Yang: New metallic materials, (Munundang, Seoul, 1995) pp. 245-246.

3) Y. B. Kim: J. Korean Foundation for Gnatho-Orthodontic Res. 2 (1995) 151-197.

4) A. C. Funk: Angle Orthod. 21 (1951) 129-138.

5) W. A. Backofen and G. F. Gales: Am. J. Orthod. 38 (1952) 755-765

6) R. W. Kohl: Angle Orthod. 24 (1964) 37-52.

7) G. L. Howe, E. H. Greener and D. S. Crimms: Angle Orthod. 38 (1968) 244-249.

8) J. H. Gardiner and A. C. Aamodt: Dent. Practit. 20 (1969) 65-76.

9) E. W. Skinner: Skinner's science of dental materials, ed. by R. W. Phillips (W. B. Saunders, Philadelphia, 1991) pp. 261-270, 537-551.

10) R. C. Thurow: Edgewise Orthodontics, (Mosby, St Louis, 1982) pp. 42-66.

11) A. Hensten-Pettersen, N. Jacobsen and M. R. Grimsdottir: Orthodontic Materials, ed. by W. A. Brantley and T. Eliades (Thieme Stuttgart, New York, 2001) pp. 287-299.

12) B. D. Cullity: Elements of X-ray diffraction, (Addison-Wesley, Massachusetts, 1978) pp. 421-446.

13) J. Neter, M. H. Kunter, C. J. Nachtsheim and W. Waserman: Applied linear statistical model, (Richard D. Irwin Inc., Chicago, 1996) pp. 779-791.

14) J. Neter, M. H. Kunter, C. J. Nachtsheim and W. Waserman: Applied linear statistical model, (Richard D. Irwin Inc., Chicago, 1996) pp. 776777.

15) K. T. Oh, Y. H. Shim, J. Y. Shin, K. M. Kim and K. N. Kim: J. Korea Res. Soc. for Dent. Mater. 27 (2000) 207-215.

16) D. F. Lane and R. J. Nikolai: Angle Orthod. 50 (1980) 139-145.

17) R. J. Nikolai: Bioengineering analysis of orthodontic mechanics, (Lea and Febiger, Philadelphia, 1985) pp. 113-144, 233-269.

18) M. R. Marcotte: J. Dent. Res. 52 (1973) 1171-1175. 